\title{
Effects of sex, mating status and temperature on flight activity of the Oriental tea tortrix, Homona magnanima (Lepidoptera: Tortricidae)
}

\author{
Yoichi Shirai, Yukio Kosugi ${ }^{1}$ and Hiroshi Noguchi \\ National Institute of Agro-Environmental Sciences, Tsukuba, Ibaraki 305-0856, Japan \\ ${ }^{1}$ Shizuoka Tea Experiment Station, Kikugawa, Shizuoka 439-0002, Japan \\ (Received 17 November 1997; Accepted 16 March 1998)
}

\begin{abstract}
Effects of sex, mating status and temperature on flight activity of the Oriental tea tortrix, Homona magnanima, were evaluated by a computer-aided flight mill system. Adult moths reared through 22 to 25 generations were used to measure flight activity. Two to 8 day-old, females always flew more than males. It is likely that survival and flight duration of males were reduced due to exhaustion resulting from flight behavior. Mating status, whether mated or unmated, did not affect flight activity in either sex. Females showed high flight ability within the temperature range from 15 to $23^{\circ} \mathrm{C}$, and their flight activity and survival greatly decreased at temperatures over $25.5^{\circ} \mathrm{C}$.
\end{abstract}

Key words: Flight activity, Homona magnanima, tea tortrix, Tortricidae

\section{INTRODUCTION}

In Shizuoka Prefecture, central Japan, one of the main tea producing areas, insecticide resistance to chlorfluazuron (chitin synthesis inhibitor), was first reported in 1993 in the Oriental tea tortrix, Homona magnanima (Uchidoi et al., 1994). Since then, rotational application of organophosphates or synthetic pyrethroids has been planned instead of use in the chitin synthesis inhibitor in Shizuoka prefecture (Y. Kosugi, unpublished data). When planning to rotate several types of insecticides to reduce the development of insecticide resistance, it is important to understand the dispersal flight ability of the target insect pest.

Homona magnanima has been considered to be a resident species which has low dispersal ability (Kawai, 1997). However, flight ability of this species has been little studied in the field or laboratory (Minamikawa and Osakabe, 1979; Tamaki, 1991). Shirai and Kosugi (1997) conducted a preliminary study on flight ability of this species using a flight mill, and showed that females of $H$. magnanima displayed a long continuous flight over at least 4 to $5 \mathrm{~km}$ a night at the age of 2 to 5 days. This study also showed that females always had greater flight duration and velocity than males, however, the num- bers of moths tested were insufficient to allow further analysis.

In the present study, the effects of age, sex, mating status and temperature on flight activity were evaluated using $H$. magnanima adults reared successively for 22 to 25 generations. In addition, body size and longevity of both sexes were measured to investigate the cause of the sexual difference in flight ability of $H$. magnanima suggested by Shirai and Kosugi (1997).

\section{MATERIALS AND METHODS}

Insects. Egg masses of $H$. magnanima were collected from a tea field in Kanaya, Shizuoka Prefecture in September 1994. Their progeny were reared under constant conditions of $25^{\circ} \mathrm{C}$ and $14 \mathrm{~L}-10 \mathrm{D}$, on an artificial diet (Noguchi, 1990), and pupae were sexed to obtain unmated moths. Developmental duration from oviposition to emergence averaged 30 days. Adults reared through 22 to 25 generations were used for measurement of flight ability. Between emergence and flight measurement, adults were placed in mesh cages $(40 \times 40 \times 40 \mathrm{~cm})$ containing $5 \%$ honey solution, under constant conditions of $23^{\circ} \mathrm{C}$ and $16 \mathrm{~L}-8 \mathrm{D}$. The following experiments were conducted from May to September 1996.

Body size and longevity of adults. For 30 in- 
dividuals of each sex, forewing length $(L)$, forewing width $(W)$ and fresh body weight $(B)$ were measured, and wing-loading $[B \div(L \times W)]$ was calculated. In addition, to evaluate adult longevity, 30 individual unmated females and males were separately placed in a mesh cage containing $5 \%$ honey solution, under constant conditions of $23^{\circ} \mathrm{C}$ and $16 \mathrm{~L}-8 \mathrm{D}$.

Flight ability measurement. The present study used the same computer-aided flight mill system and rotor as used for the studies of Hellula undalis (Kawamoto et al., 1987) and Crocidolomia binotalis (Shirai and Nakamura, 1995). Flight measurements, except for the experiment on effect of temperature, were made continuously over a 24 -h period at $23^{\circ} \mathrm{C}$, with illuminance of $10 \mathrm{~lx}$. Non-flier moths, which did not fly at all during the tethered flight examination, were excluded from the data of flight ability. Flight ability was represented in terms of three measures: total flight duration, flight velocity, and proportion of individuals showing continuous flight for more than $2 \mathrm{~h}$ (henceforth abbreviated as continuous flight).

Age-specific flight ability of both sexes. Flight ability of unmated females and males was measured at the ages of $1,2,3,4,5$ and 8 days, using 32 to 37 individuals for each group.

Effects of mating status on flight activity. Homona magnanima begins to mate successfully 2 days after emergence, and oviposits the following day in the laboratory (Noguchi, 1990). To obtain mated adults, 30 pairs of females and males were placed for 3 days in a mesh cage at $23^{\circ} \mathrm{C}$ and $16 \mathrm{~L}-8 \mathrm{D}$. Flight ability of mated moths was then measured for 3 dayold females and 4 day-old males. As not all individuals mated in the mesh cage, only individuals for which mating was confirmed were adopted for flight measurement. The flight ability of unmated moths was obtained in the experiment described above.
Effects of temperature on flight activity. Flight ability of 5 day old unmated females was evaluated over a 24 -h period at seven different temperatures $(15.5,18.0,20.5,23.0,25.5,28.0$, and $30.5^{\circ} \mathrm{C}$ ), with illuminance of $10 \mathrm{~lx}$. Twenty seven to 35 individuals were measured for each group. The value at $23.0^{\circ} \mathrm{C}$ was obtained from examination of the age-specific flight ability described above.

\section{RESULTS}

\section{Body size and longevity of adults}

Forewing length, forewing width and fresh body weight of females were significantly greater than those of males. Wing-loading and longevity did not differ significantly between the sexes (Table 1).

\section{Age-specific flight ability of both sexes}

Figure 1 compares the flight ability of both sexes at 1 to 8 days old. There were no significant differences in the proportion of non-flier moths, which showed no flight behavior, between the sexes at any age ( 1 to 8 days old). Flight duration of females tended to be longer than that of males at every age and it was significantly longer at 3 to 5 days. Flight velocity of males was significantly higher than that of females at 4 days, but the values at other ages did not differ significantly between the sexes. The proportion of continuous flights tended to be higher in males than in females at 2 days, while that of females was higher at 3 to 8 days. As a whole, females displayed greater flight ability than males after 3 days. At the termination of the tethered flight examination, females always survived better than males and the survival rate at 4 days differed significantly between the sexes.

\section{Effect of mating status on flight activity}

Figure 2 compares the flight ability of mated

Table 1. Body size and longevity of Homona magnanima adults

\begin{tabular}{lccccccc}
\hline Sex & $n$ & $\begin{array}{c}\text { Forewing length } \\
(\mathrm{mm})\end{array}$ & $\begin{array}{c}\text { Forewing width } \\
(\mathrm{mm})\end{array}$ & $\begin{array}{c}\text { Fresh body weight } \\
(\mathrm{mg})\end{array}$ & $\begin{array}{c}\text { Wing-loading } \\
\left(\mathrm{mg} / \mathrm{mm}^{2}\right)\end{array}$ & $n$ & Longevity (days) \\
\hline Female & 30 & $14.0 \pm 1.2$ & $4.5 \pm 0.5$ & $13.6 \pm 4.5$ & $0.2094 \pm 0.0414$ & 30 & $11.4 \pm 3.5$ \\
Male & 30 & $11.3 \pm 0.7^{* *}$ & $3.4 \pm 0.4^{* *}$ & $7.0 \pm 1.8^{* *}$ & $0.1844 \pm 0.0384^{\mathrm{ns}}$ & 30 & $9.3 \pm 3.7^{\mathrm{ns}}$ \\
\hline
\end{tabular}

Mean \pm SD. ${ }^{* *} p<0.01$, ns: $p>0.05$ (by $t$-test). 

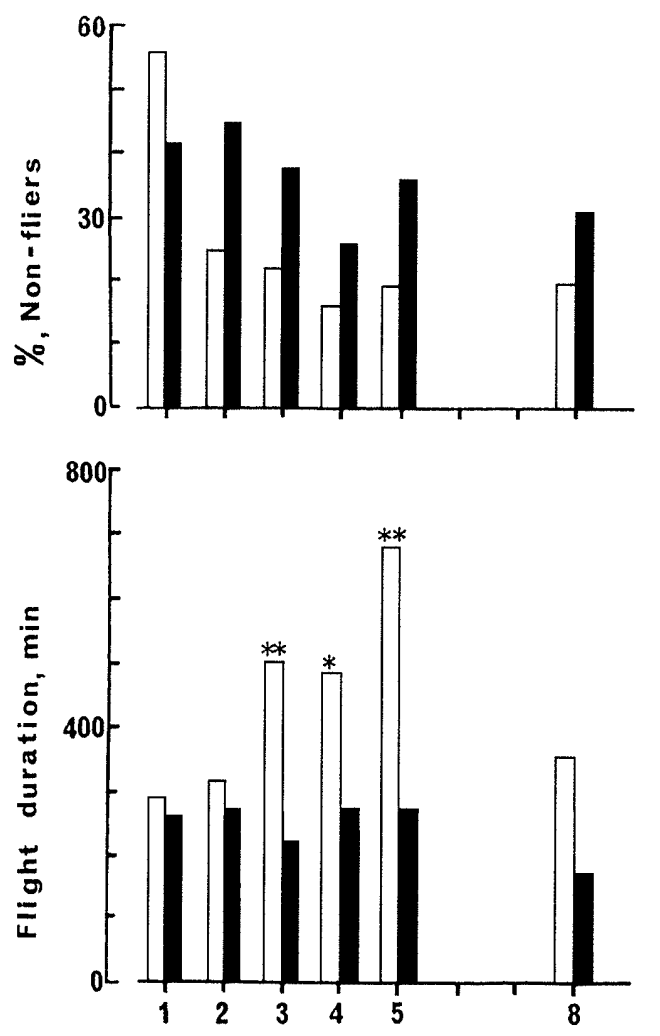
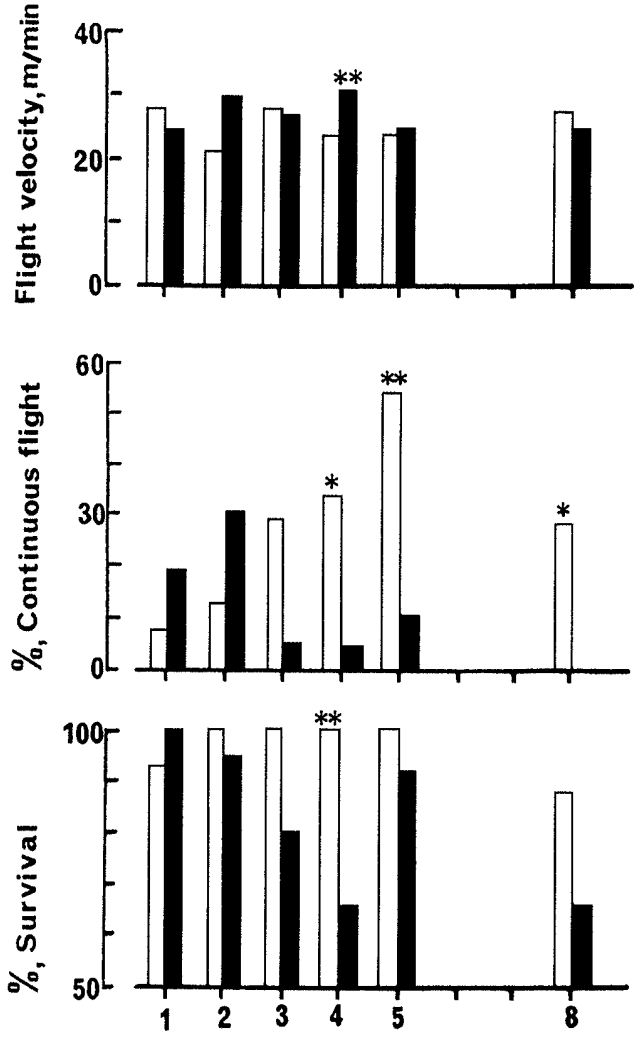

Age in days

Fig. 1. Age-specific flight ability of unmated females ( $\square$ ) and males ( $\square$ ) of Homona magnanima. ${ }^{*}(0.01<p<0.05)$ and ${ }^{* *}(p<0.01)$ show significant differences between sexes of the same age by Mann-Whitney $U$-test (flight duration and flight velocity) and $\chi^{2}$-test (proportion of non-fliers, proportion of continuous flight, and survival rate).

and unmated adults for 3 day-old females and 4 day-old males. Mating status did not influence any flight parameter (the proportion of non-flier moths, flight duration, or proportion of continuous flights) in either sex.

\section{Effect of temperature on flight activity}

Figure 3 shows the flight ability and survival rate at the termination of the flight experiment of 5 day-old unmated females under seven different temperature conditions. The proportion of non-flier moths did not significantly differ at any temperature. Females flew for the longest time at $23^{\circ} \mathrm{C}$ and the shortest at $30.5^{\circ} \mathrm{C}$. Flight duration tended to decrease considerably at temperatures over $25.5^{\circ} \mathrm{C}$. The highest and lowest flight velocities were found at $30.5^{\circ} \mathrm{C}$ and $18^{\circ} \mathrm{C}$, respectively; however, there was no clear relationship between flight velocity and temperature. Maximum and minimum proportions of continuous flights were recorded at $23^{\circ} \mathrm{C}$ and $28^{\circ} \mathrm{C}$, respectively. The survival rate after flight examination tended to decrease above $25.5^{\circ} \mathrm{C}$.

\section{DISCUSSION}

\section{Sexual difference in flight ability}

In the present study, females of $H$. magnani$m a$ always showed greater flight ability than males, and males could not take a long continuous flight, especially when over 3 days old. This result accorded well with our previous study (Shirai and Kosugi, 1997) in which adults reared for three generations were used. Males of $H$. magnanima have been thought to fly more actively than females, because a larger number of males were captured by light traps in tea fields (Minamikawa and Osakabe, 1979). However, the present study suggests that females may actually make longer distance flights in the field than males.

As females have significantly larger body size (Table 1), the sexual difference in flight ability may result from differences in vitality or body size of adults. With many species of lepidop- 

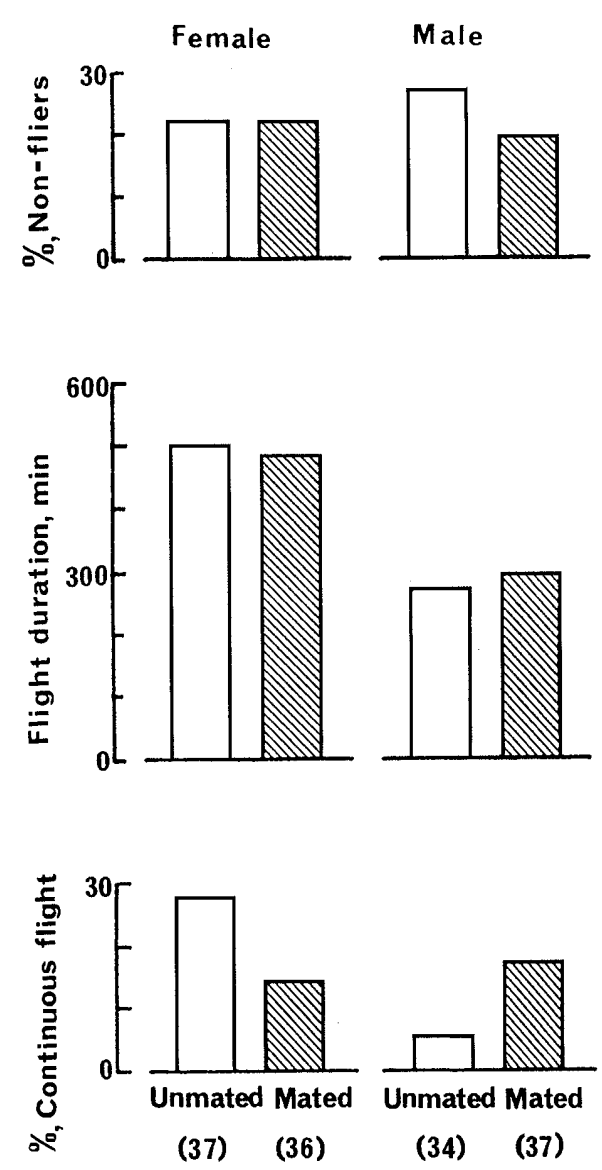

Fig. 2. Comparison of flight ability between unmated and mated moths. Three day-old females (left), 4 day-old males (right). The numbers in parentheses show the total number of moths tested. No comparisons showed significant differences $(p>0.05)$ by $\chi^{2}$-test (proportion of non-fliers and proportion of continuous flight) and by Mann-Whitney $U$-test (flight duration).

terous insects, flight ability increases with body size [refer to Shirai (1993) for detailed literature]. In $H$. magnanima, as body weight also decreased with wing size, wing-loading did not significantly differ between the sexes (Table 1). In this type of insect, smaller individuals appear to be more energetically exhausted by flight behavior (Hammond and Fescemyer, 1987). Males of $H$. magnanima have wing beats as strong as those of females, because the males flew significantly faster than females at 4 days, and the flight velocity at other ages did not differ between the sexes (Fig. 1). Survival and flight durations of males may be reduced due to exhaustion resulting from flight behavior.

Most females of $H$. magnanima complete mating within 2 or 3 days after emergence (Noguchi, 1990), and flight ability did not differ between mated and unmated females (Fig. 2).
Therefore, this species might be able to emigrate to a new habitat and become established there, even if only the females have greater flight ability. Presumably, poor flight ability of males is not very unfavorable to reproductive success in the new habitat. On the other hand, in the light brown apple moth, Epiphyas postvittana (Tortricidae), the relationship between body size and flight ability of both sexes was quite different from the present results; females of $E$. postvittana have a larger body size than males, but their flight ability was inferior to that of males according to a tethered flight experiment $(\mathrm{Gu}$ and Danthanarayana, 1992). This sexual difference in flight activity was also confirmed in the field (Suckling et al., 1994). As flight ability of males has been less studied compared with that of females (Johnson, 1969; Gatehouse and Zhang, 1995), it is necessary to accumulate more data concerning male flight in relation to reproduction.

\section{Estimation of flight activity in the field}

As measured by total flight duration, proportion of continuous flights, and survival rate (Fig. 3), females could maintain high flight ability and longevity within the temperature range from 15.5 to $23^{\circ} \mathrm{C}$, while temperatures over $25.5^{\circ} \mathrm{C}$ were less suitable for both flight and survival. Adults of $H$. magnanima are found from mid-April to mid-November in central Japan (Minamikawa and Osakabe, 1979), and population density becomes generally higher in the summer and autumn (Tamaki, 1991). In mid summer, flight activity of $H$. magnanima may be reduced by high temperatures. Even at the lower temperature of $15.5^{\circ} \mathrm{C}$, females showed high flight ability, similar to the values obtained at $23^{\circ} \mathrm{C}$ (Fig. 3). Homona magnanima appears to fly actively at temperatures of 15 to $16^{\circ} \mathrm{C}$ in the field, since a large number of moths were captured during the midnight in October when the minimum temperature was below $16^{\circ} \mathrm{C}$ in Shizuoka Prefecture (M. Ohtaishi, unpublished data).

In the present study, 5 day-old females were capable of flying $11.4 \mathrm{~h}(18.9 \mathrm{~km})$ a day (Fig. 1). However, as flight ability in the present study was measured continuously over a $24-\mathrm{h}$ period, using a tethered flight mill, the actual flight 

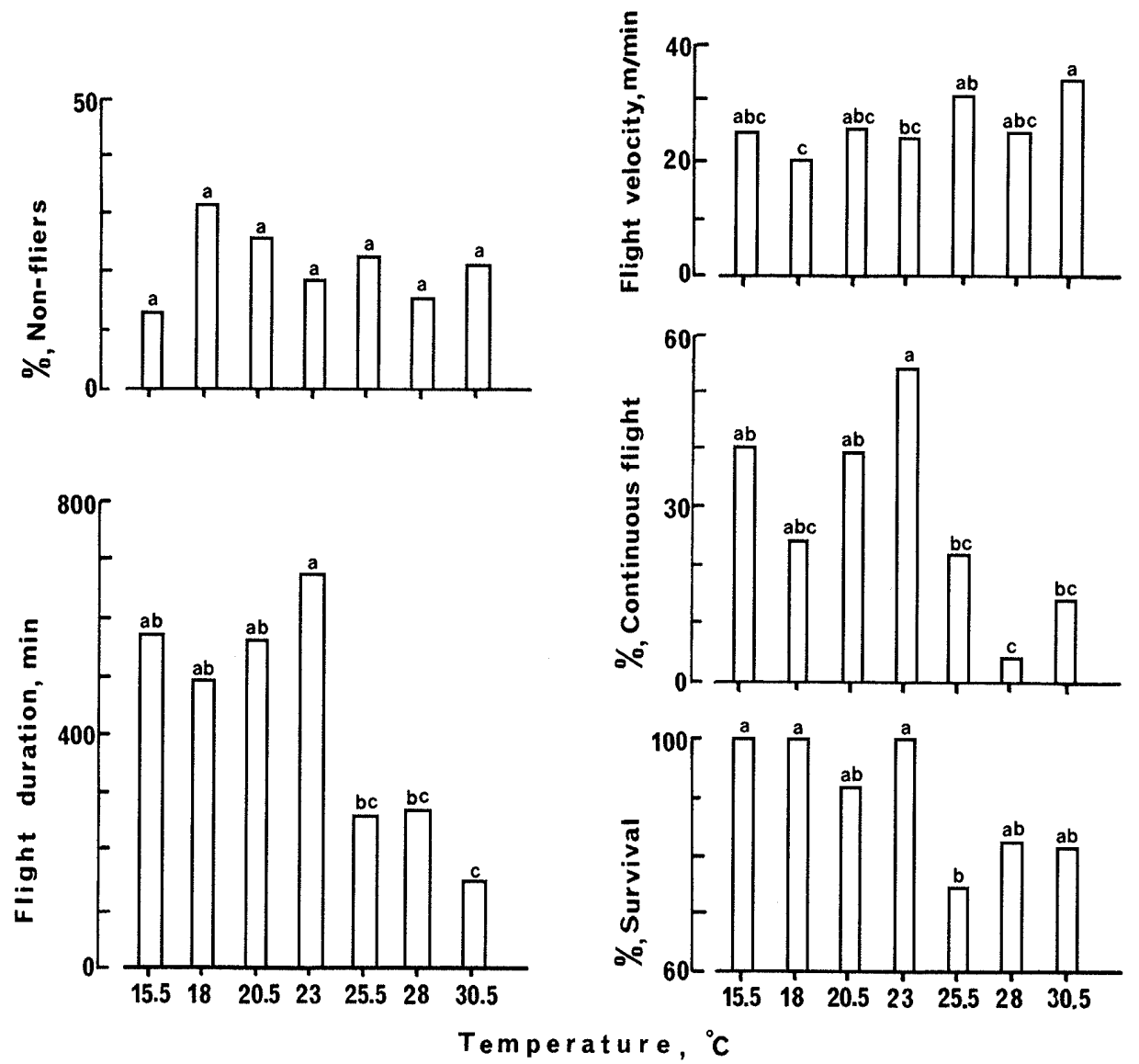

Fig. 3. Effects of temperature conditions on flight ability of unmated 5 day-old females. Bars with different letters are significantly different $(0.01<p<0.05)$ by Kruskal-Wallis test, Dunn multiple comparison (flight duration and flight velocity) and $\chi^{2}$-test (proportion of non-fliers, proportion of continuous flight, and survival rate).

distance in the field could not be estimated directly from these flight data. We assumed that females of $H$. magnanima fly at a velocity of 1.6 $\mathrm{km}$ per hour on average, derived from $26.0 \mathrm{~m}$ per minute shown in Fig. 1, and that they fly actively for $3 \mathrm{~h}$ a night, since this species is most fluently attracted to light traps between 22:00 and 24:00 (Minamikawa and Osakabe, 1979). Females could thus travel about $4.8 \mathrm{~km}$ a night.

Some field studies on dispersal and flight movement of other tortricids have been conducted using pheromone trap networks or mark-release-recapture methods. Males of the summer fruit tortrix moth, Adopxophyes orana, flew 70 to $100 \mathrm{~m}$ a night (Van der Kraan and Van Deventer, 1982). The pea moth, Cydia nigricana, was estimated to make short distance flights of 100 to $200 \mathrm{~m}$ a night (Wall and Perry, 1980). On the other hand, the lesser peach tree borer, Synanthedon pictipes (Sesiidae), flew 800 $\mathrm{m}$ on average (Karandinos, 1974). Van der
Kraan and Van Deventer (1982) suggested that the lower flight capacity of tortricids such as $A$. orana may be partly attributable to the fact that they always live in the dense foliage of an orchard.

Field studies on insect dispersal flight should indicate the meteorological data extant when the study was conducted, since the flight distance estimated from the field experiments often varies widely according to wind or temperature conditions (Solomon, 1991). Some Tortricidae showed greater flight ability in the field. For example, males of Planotortrix octo and Epiphyas postvittana were able to fly at least $400 \mathrm{~m}$ and $600 \mathrm{~m}$, respectively, in an apple field in New Zealand (Suckling et al., 1994). Cydia funebrana was estimated to travel at least several kilometers in large stoned fruit orchards in Hungary (Sziraki, 1982). Both field and laboratory studies are needed for further understanding of flight activity. Dispersal flight of $H$. 
magnanima should be studied in a large tea field, using pheromone or light traps and mark-release-recapture methods.

\section{ACKNOWLEDGEMENTS}

We thank Dr. Akira Kawai (National Research Institute of Vegetables, Ornamental Plants and Tea, Kanaya, Shizuoka) for his valuable comments on an earlier draft of the manuscript. Cordial thanks are also given to two anonymous referees for constructive criticism on the manuscript.

\section{REFERENCES}

Gatehouse, A. G. and X. X. Zhang (1995) Migration potential in insect: variation in an uncertain environment. In Insect Migration (V.A. Drake and A.G. Gatehouse eds.). Cambridge University Press, Cambridge, pp. 193-242.

$\mathrm{Gu}, \mathrm{H}$. and W. Danthanarayana (1992) Influence of larval rearing conditions on the body size and flight capacity of Epiphyas postvittana moths. Aust. J. Zool. 40: 573-581.

Hammond, A.M. and H.W. Fescemyer (1987) Physiological correlates in migratory noctuids: the velvetbean caterpillar as a model. Insect Sci. Appl. 8: 581-589.

Johnson, C. G. (1969) Migration and Dispersal of Insects by Flight. Methuen, London.

Karandinos, M. G. (1974) Recovery of Synanthedon pictipes males released at various distances of downwind of sex pheromone traps. Environ. Entomol. 3: 923-925.

Kawai, A. (1997) Prospect for integrated pest management in tea cultivation in Japan. JARQ 31: 213-217.

Kawamoto, K., Y. Shirai and T. Okada (1987) Preliminary studies on the flight ability of the cabbage webworm, Hellula undalis (Lepidoptera, Pyralidae), using a flight mill system. Bull. Natl. Res. Inst. Veg., Ornam. Plants Tea, Ser. A 1: 147-160 (in Japanese with English summary).

Minamikawa, J. and M. Osakabe (1979) Injurious Insects on Tea Plant. Japan Plant Protection Association, Tokyo (in Japanese).
Noguchi, H. (1990) Studies on comparative physiology of behaviors and sex pheromones of the tea tortrix moth and the smaller tea tortrix moth. Bull. Natl. Inst. Agro-Environ. Sci. No. 7: 73-138 (in Japanese with English summary).

Shirai, Y. (1993) Factors influencing flight ability of male adults of the diamondback moth, Plutella xylostella, with special reference to temperature conditions during the larval stage. Appl. Entomol. Zool. 28: 291-301.

Shirai, Y. and S. Nakamura (1995) Laboratory evaluation of flight ability in the cabbage head caterpillar, Crocidolomia binotalis Zeller (Lepidoptera, Pyralidae). Jpn. J. Ent. 63: 841-850.

Shirai, Y. and Y. Kosugi (1997) Preliminary evaluation of the flight ability in the oriental tea tortrix, Homona magnanima. Proc. Kanto-Tosan Plant Prot. Soc. 44: 259-261 (in Japanese with English summary).

Solomon, M.E. (1991) Ecology and population dynamics. In Tortricid Pests (L.P.S. Van der Geest and H. H. Evenhuis eds.). Elsevier Science Publishers, Amsterdam, pp. 209-234.

Suckling, D. M., J. F. Brunner, G. M. Burnip and J. T. S. Walker (1994) Dispersal of Epiphyas postvittana and Planotortrix octo (Lepidoptera: Tortricidae) at a Canterbury, New Zealand orchard. N. Z. J. Crop Hort. Sci. 22: 225-234.

Sziraki, G. (1982) The dispersal habits of important moth pests (Tortricidae) of large-scale stone fruit orchards. Novenyvedelem 18: 494-501 (in Hungarian with English summary).

Tamaki, Y. (1991) Tortricids in tea. In Tortricid Pests (L. P.S. Van der Geest and H.H. Evenhuis eds.). Elsevier Science Publishers, Amsterdam, pp. 541-551.

Uchidoi, T., Y. Mori and K. Asahina (1994) Decline in the susceptibility of oriental tea tortrix to benzoyl phenyl urea insecticides in Shizuoka Prefecture. Proc. Kanto-Tosan Plant Prot. Soc. 41: 261-263 (in Japanese).

Van der Kraan, C. and P. Van Deventer (1982) Range of action and interaction of pheromone traps for the summer fruit tortrix moth, Adopxophyes orana. J. Chem. Ecol. 8: 12511262.

Wall, C. and J.N. Perry (1980) Effects of spacing and trap number on interactions between pea moth pheromone trap. Entomol. Exp. Appl. 28: 313-321. 